\title{
DEATH BY WATER: CONFLUÊNCIAS ENTRE MÁRIO FAUSTINO E T. S. ELIOT
}

\author{
Dayana Crystina Barbosa de Almeida* \\ Universidade Federal do Sul e Sudeste do Pará \\ Izabela Guimarães Guerra Leal ${ }^{* *}$ \\ Universidade Federal do Pará
}

\begin{abstract}
Resumo: Mário Faustino, além de poeta, foi também tradutor, exercendo essa atividade em diferentes momentos de sua carreira e, por meio de suas traduções, dialogou com diversos autores, tornando-os parte de sua obra. Assim, a partir da comparação entres os poemas "Nam Sibyllam" e "Death by water", este artigo busca mostrar como Faustino deu origem a um novo poema a partir da obra de Eliot.
\end{abstract}

Palavras-chave: Mário Faustino. T. S. Eliot. Tradução.

\footnotetext{
* Possui graduação em Letras Licenciatura Habilitação em Língua Inglesa e mestrado em Letras Estudos Literários ambos pela Universidade Federal do Pará. Doutoranda em Letras Estudos Literários pela Universidade Federal do Pará. Atualmente é professora Assistente do Instituto de Letras, Linguística e Artes da Universidade Federal do Sul e Sudeste do Pará (UNIFESSPA). Marabá, Pará, Brasil. E-mail: almeidadcb@gmail.com

** Possui graduação em Psicologia e mestrado em Literatura Portuguesa (PUC Rio). Doutorou-se em Literatura Portuguesa pela Universidade Federal do Rio de Janeiro (UFRJ), em 2008. Atualmente é professora Adjunta da Faculdade de Letras (UFPA) e do Programa de Pós-Graduação em Letras (UFPA). Belém, Pará, Brasil. E-mail: izabelaleal@gmail.com
} 


\title{
DEATH BY WATER: CONFLUENCES BETWEEN MÁRIO FAUSTINO AND T. S. ELIOT
}

\begin{abstract}
Mario Faustino, besides being a poet, was also a translator, exercising this profession in different moments of his career. Through his translations, he dialogued with several authors, making them part of his work. Thus, based on the comparison between the poems "Nam Sibyllam" and "Death by water", this article seeks to demonstrate how Faustino create a new poem from Eliot's work, taking into account the notion of intertextuality of Kristeva.
\end{abstract}

Keywords: Faustino. Eliot. Translation.

Todo texto se constrói como mosaico de citações, todo texto é absorção e transformação de um outro texto; ele é uma escritura-réplica (função e negação) de outro (dos outros) texto(s). (KRISTEVA, 1974)

O suplemento literário intitulado Arte-Literatura, do jornal paraense Folha do Norte, foi o lugar em que o poeta Mário Faustino trabalhou no início de sua carreira como escritor, publicando seus primeiros poemas, contos e traduções. Faustino, juntamente com Ruy Guilherme Barata, Paulo Plínio Abreu, Carlos Drummond de Andrade, Manuel Bandeira, Cecília Meireles e Aurélio Buarque de Holanda, traduziu vários autores estrangeiros no referido suplemento entre os anos 1946 e 1951.

Faustino traduziu os poemas de Rafael Alberti "Minha corça" e "Se eu fosse embora, amada"; os poemas de Juan Ramón Jimenez, "Desnudos" e "Coisas impossíveis"; o poema de Rilke "A Grande noite"; o poema de Afonsina Storni "Homem pequenino"; o conto de James Joyce "Eveline", e ainda fez uma tradução do poema "Death by water" de T. S. Eliot. Posteriormente, traduções de poemas de Eliot foram publicadas outras duas vezes no Arte-Literatura: "Um canto por Simeão" por Paulo Mendes Campos, em 1949 e a "A Viagem dos Magos” por um anônimo, em 1950.

Faustino deu continuidade ao seu ofício de tradutor quando dirigiu, de 1956 a 1959, o suplemento literário Poesia-Experiência, 
do Jornal do Brasil. No livro Poesia Completa Poesia Traduzida (1985), Benedito Nunes tentou reunir todas as traduções feitas por Mário Faustino, e, embora a lista seja extensa - há poemas traduzidos de Horácio, Shakespeare, Goethe, Hölderlin, Pound, cummings, Brecht e Artaud -, está incompleta, pois não constam, por exemplo, traduções de poemas como "Transfiguração" e "Antípodas à vista", do poeta norte-americano Robert Stock, publicadas somente no ano de 2012, em uma plaquete intitulada Meretriz imaginária e também não foram incluídas as traduções feitas no Arte-Literatura, à exceção de "Death by water". A inclusão do poema de Eliot neste livro pode ter uma explicação inicial na nota escrita pelo próprio Benedito Nunes:

\begin{abstract}
Os poemas traduzidos, alguns datando da adolescência do autor, outros procedentes de 'Poesia-Experiência', pertencem ao seu universo poético tanto quanto a crítica de poesia a que se dedicou, como organizador dessa Página do Suplemento Dominical do Jornal do Brasil. (NUNES, 1985, p. 10).
\end{abstract}

Podemos inferir que a poesia de Faustino resulta da soma de poetas que ele leu, em diferentes momentos, tais como: Mallarmé, Yeats, Rilke, cummings, Joyce e Pound, deste último utilizou o lema "repetir para aprender, criar para renovar" ${ }^{\text {. O lema de }}$ Pound remete direta ou indiretamente à presença de outros autores em alguns poemas de Faustino, como é o caso de T. S. Eliot, cujas ideias se refletiram em seu trabalho crítico, e que também está presente no poema "Nam Sibyllam".

\title{
1. A ruptura de hierarquias entre a literatura nacional e a estrangeira
}

Julia Kristeva, a cunhadora do termo intertextualidade, esclarece que o texto literário nunca é algo isolado, e sim um cruza- 
mento de planos textuais, de conversas entre diferentes escrituras que apontam para o próprio escritor, o destinatário e o contexto cultural atual ou anterior (KRISTEVA, 1974, p.62). Por meio de diálogos intertextuais é possível perceber o mecanismo que engendra a produção de um novo texto, incluindo processos de rapto, absorção e integração de elementos alheios na criação da obra nova, o que não significa pensar em termos de "influência" ou mesmo da relação entre modelo e cópia.

Silviano Santiago (1978), no ensaio "O entre-lugar do discurso latino-americano", sugere uma discussão acerca das noções e implicações dos conceitos de modelo e de cópia quando se analisa a relação entre as literaturas latino-americanas e as literaturas europeias. Para o autor, não está mais em questão o uso das noções de original e cópia, ou de fonte e influência, o que estabeleceria $\boldsymbol{a}$ priori uma hierarquização das obras literárias, sendo os modelos europeus considerados superiores às "imitações" que surgem na América latina. As noções de modelo e cópia colocam em evidência um conceito de valor que é determinado por condições históricas. Consequentemente, vem à tona uma ideia de dependência das culturas das ex-colônias em relação às ex-metrópoles e os impasses que se originam a partir daí são irremediáveis.

Para escapar desse determinismo, Silviano Santiago já chamara a atenção para o processo de "interiorização do exterior", imprescindível à formação cultural brasileira, relendo de forma crítica a Poesia Pau Brasil, de Oswald de Andrade. Silviano sugere que a antropofagia de Oswald já antecipava questões muito atuais ao fazer uma nova leitura da dinâmica desempenhada pelo jogo de forças entre interior/exterior, colonizado/colonizador. Santiago esquematiza a questão do seguinte modo:

Para o Brasil poder se exteriorizar com dignidade é preciso que acate antes o exterior em toda a sua concretude. A consciência nacional estará menos no conhecimento do seu interior e no complexo processo de interiorização do que lhe é exterior, isto é, do que lhe é estrangeiro. (SANTIAGO, 2006, p.135). 
Eneida Maria de Souza (2007, p.51), em " $O$ discurso crítico brasileiro", acrescenta, mediante o confronto entre o já citado artigo de Santiago (1982) e o de Haroldo de Campos, "Da razão antropofágica: diálogo e diferença na cultura brasileira" (1983), que ambos os textos retomam a antropofagia como "conceito operatório", que ainda se mostra eficaz "no processo de desconstrução das culturas estrangeiras". Desse modo, a literatura nacional é pensada em termos de igualdade em relação à estrangeira, por meio da certeza no aspecto positivo da transculturação.

\section{2. "Death by water": o legado de Eliot}

Maria Eugênia Boaventura, a organizadora de obras de Faustino como "Artesanatos de Poesia" (2004), "De Anchieta aos Concretos" (2003) e "O homem e sua hora" (2009), em seu ensaio "Um militante da poesia" (2009), diz-nos que Mário Faustino objetivava manter distância, no mínimo do ponto de vista teórico, "da aparente facilidade estético-formal modernista e nada mais sintomático do que o encantamento por modelos de poesia como a de Yeats, Eliot etc." (2009, p. 33). Poderíamos complementar dizendo que, de acordo com Benedito Nunes (1985), Faustino obteve lenta assimilação dos melhores padrões da linguagem poética das literaturas brasileira e portuguesa, pelas poesias francesa e alemã e pelos poetas da língua inglesa, dentre os quais destaca T. S. Eliot, por tê-lo influenciado de modo positivo, mas de quem ele se afastou rapidamente.

Benedito Nunes (1977) afirma:

É possível identificar diálogos entre 'O homem e sua hora' e 'Invenção de Orfeu', como, por exemplo, as diversas citações nas duas línguas clássicas ou em modernas línguas estrangeiras, localizadas ao longo de ambos, recurso destacado por Faustino no primeiro número da página 'Poesia-experiência', pelo uso que dele fez Eliot, para quem este 
intercâmbio de línguas constituía um fator de revitalização da literatura. (NUNES, 1977, p. 278).

De acordo com a citação de Nunes, ocorreu uma confluência entre Mário Faustino e Eliot por meio do uso de citações em línguas clássicas, bem como em línguas estrangeiras modernas em busca da revitalização da literatura no poema "O homem e sua hora" e, podemos acrescentar, no poema "Nam Sibyllam", a partir do qual surgiu, ainda em Belém, a confluência entre Mário Faustino e T. S. Eliot, quando Faustino foi colaborador do suplemento literário Arte-Literatura, do jornal Folha do Norte, e traduziu "Death by water”. Nesta época, de acordo com Marinilce Coelho (2008), em sua tese "Memórias literárias de Belém do Pará: o Grupo dos Novos, 1946-1952", Faustino fez parte do "Grupo dos Novos", alcunha dada a si mesmos pelos poetas da geração literária de 1940 em Belém. Os membros deste grupo, assim como autores e críticos já conhecidos pelo público, mas, principalmente da geração de jovens poetas, ficcionistas e críticos estreantes no mundo literário, utilizaram o Arte-Literatura como meio de divulgação da sua produção literária e crítica.

Esse suplemento exerceu importante papel para a formação de literatos e críticos devido ao conteúdo que divulgava em suas páginas (COELHO, 2003, p.12). Em suma, o suplemento reuniu uma nova geração da literatura brasileira, anunciando um pensamento aberto em relação às literaturas estrangeiras. Passemos à tradução de Faustino do poema de Eliot:

Death by water ${ }^{2}$

Poema de T. S. ELIOT

Phlebas the Phoenician, a fortnight dead, Forgot the cry of gulls, and the deep sea swell

And the profit and loss.
Tradução de MÁRIO FAUSTINO

Phlebas, o fenício, morto há quinze dias, Esqueceu-se do grito das gaivotas e da profunda ondulação do mar E dos lucros e perdas. 
A current under sea

Picked his bones in whispers.

As he rose and fell

He passed the stages of his age and youth

Entering the whirlpool.

Gentile or Jew

O you who turn the wheel and look to windward,

Consider Phlebas, who was once

handsome and tall as you
Uma corrente submarina

Picou-lhe os ossos, murmurando. E subindo e descendo

Ele passou o tempo da velhice e da juventude

E penetrou na voragem.

Ó vós todos, judeus ou gentios, Vós que moveis o leme e olhais a barlavento

Lembrai-vos de Phlebas, que foi um dia belo e alto como vós.

(De "The Waste Land")

Há, primeiramente, um dado importante a respeito de "Death by Water": trata-se de uma curta versão das últimas sete linhas do poema "Dans le Restaurant", escrito em francês por Eliot e publicado em 1920, antes de "The Waste Land", publicado em 1922:

Dans le Restaurant

“(...) Phlébas, le Phénicien, pendant quinze jours noyé, Oubliait les cris des mouettes et la houle de Cornouaille, Et les profits et les pertes, et la cargaison d'étain:

Un courant de sous-mer l'emporta très loin,

Le repassant aux étapes de sa vie antérieure.

Figurez-vous donc, c'était un sort pénible;

Cependant, ce fut jadis un bel homme, de haute taille".

(ELIOT, 2004, p. 28) 
Numa carta a Ezra Pound, seu amigo de longa data, Eliot comenta o poema "Dans le Restaurant", de sua autoria. Pound então envia a Eliot a sua tradução do original francês para o inglês:

Phlebas the Phenicien, fairest of men, Straight and tall, having been born in a caul Lost luck at forty, and lay drowned Two long weeks in sea water, tossed of the streams under sea, carried of currents

Forgetful of the gains forgetful of the long days of sea fare Forgetful of mew's crying and the foam swept coast of Cornwall,

Born back at last, after days to the ports and stays of his young life, A fair man, ports of his former seafare thither at last

De acordo com Susan Dick (1989) essa tradução de Pound era na realidade uma interpretação livre do que ele havia compreendido de "Dans le Restaurant". Neste caso, podemos perceber que ocorreram diversas reescritas. Primeiro temos Eliot que escreve "Dans le Restaurant" em francês, depois recebe de Pound uma tradução para o inglês. Então Eliot, baseado na tradução de Pound, retraduz seu próprio poema, muda o título para "Death by water" e o incorpora no "The Waste Land". Anos depois Faustino veio a traduzir "Death by water" do inglês para o português e depois o incorporou em sua própria obra, como será mostrado na seção seguinte.

\section{Faus(Elio)Tino: a intertextualidade entre Eliot e Faustino}

"Death by water", na realidade, é a quarta e menor seção do poema "The Waste Land", do próprio Eliot, que possui cinco se- 
ções. Esta seção IV descreve um homem, Phlebas, o fenício, que aparentemente morreu por afogamento. Quando morto, ele se esqueceu de suas preocupações mundanas, assim que as criaturas do mar lhe despedaçaram o corpo. O narrador do poema pede ao leitor que reflita sobre Phlebas e recorde a sua própria mortalidade.

A seção IV possui oito linhas divididas em quatro pares de dísticos rimados, e é uma das partes mais formalmente organizadas do poema. Benedito Nunes (2009b) nos diz que o poema The Waste Land possui um nexo transversal da Filosofia com a Poesia, pois este é um poema composto de fragmentos que "responde à laceração moral e espiritual do mundo moderno" (NUNES, 2009b, p.28). Nunes cita a fala do heterônimo de Antonio Machado, Juan de Mairena: "Há homens, dizia meu professor, que vão desde a Poética à Filosofia, outros que vão da Filosofia à Poética. É inevitável ir de um para o outro e vice-versa"3 (MACHADO, 1986, p. 166). Nunes afirma que a primeira parte do percurso de ida e vinda, exposto anteriormente, poderia descrever o movimento intelectual de certos poetas, como: Antonio Machado, Fernando Pessoa, Carlos Drummond de Andrade, João Cabral de Melo Neto, Rilke, Paul Valéry, Eliot, em direção à Filosofia; a segunda parte do percurso exporia a órbita de filósofos como: Sartre, Merleau-Ponty, Heidegger, Hannah Arendt, Gaston Bachelard, Michel Foucault, Ludwig Wittgenstein e Paul Ricœur em direção à poesia. Nunes finaliza dizendo que:

Num confronto desse tipo há, de início, duas consequências importantes: apesar do traspasse ou da mútua conversão dos termos, poeta e filósofo conservam cada qual a sua identidade própria; e, ainda, o traspasse deixa patente que filosofia e poesia, longe de serem unidades fixas, monádicas, sem janelas, mantendo entre si conexão unívoca e hierárquica, à maneira de duas disciplinas distintas, conforme nos legou a tradição clássica que Hegel averbou ao absorver a poesia na filosofia, são unidades móveis, em conexão recíproca. (NUNES, 2009, p. 29). 
O poema "Nam Sibyllam" será publicado por Faustino no livro "O homem e sua hora", cinco anos após a tradução de "Death by water" no Arte-Literatura. Podemos perceber a relação de intertextualidade entre Faustino e Eliot, pois o título do poema, "Nam Sibyllam", é o começo da epígrafe apresentada em The Waste Land, que Eliot havia retirado do capítulo XLVIII do livro Satyricon, de Petrônio: "Crês tu que eu, que vos falo, vi com meus próprios olhos a Sibila de Cumes suspensa em uma garrafa? Quando os garotos lhe perguntavam: 'Sibila, que queres?' - ela respondia: 'Quero morrer'”. (PETRÔNIO, 2004, p.62)

Lilia Chaves (2011, p. 377), no texto "O filósofo e o poeta" transcreve algumas reflexões de Benedito Nunes a respeito do poema "Nam Sibyllam". O primeiro destaque de Nunes remete ao título, Nam Sibyllam, que ele acreditava ser muito expressivo. Para ele, Faustino se utilizou da figura das Sibilas, que eram profetisas, para torná-las porta-vozes do presságio descrito no poema. Benedito Nunes também afirma que o fato de a expressão Nam Sibyllam não estar aspeada lhe fez acreditar que Faustino tenha se apropriado da mesma. Nunes então explica que "O nam significa 'ora pois': Ora pois, Sibila...”. Lilia Chaves (idem, p.378) destaca ainda que Benedito Nunes relacionou o poema "Nam Sibyllam" às estampas das próprias Sibilas, as quais estão presentes no teto da capela Sistina, assim como em canções gregas, bem como em versos de outros autores.

Para Bender (2008), em sua dissertação de mestrado "O homem e seu tempo na poesia de Mário Faustino", em "Nam Sibyllam” são fortemente notados os traços típicos do lirismo moderno, como a incorporação de elementos diversos e a ambiguidade de sentidos. Podemos observar abaixo o poema "Nam Sibyllam":

Lá onde um velho corpo desfraldava As trêmulas imagens de seus anos;

Onde imaturo corpo condenava Ao canibal solar seus tenros anos; Lá onde em cada corpo vi gravadas 
Lápides eloquentes de um passado

Ou de um futuro arguido pelos anos;

Lá cândidos leões alvijubados

Às brisas temporais se espedaçavam

Contra as salsas areias sibilantes;

Lá vi o pó do espaço me enrolando

Em turbilhões de peixes e presságios -

Pois na orla do mundo as delatantes

Sombras marinhas, vagas, me apontavam.

(FAUSTINO, 2009, p. 85)

Bender (2008, p.109) acrescenta que as imagens diretas, presentes no poema, são excedidas por um amplo "afluxo de metáforas", que pode ser observado no quarto verso "Ao canibal solar seus tenros anos". Este verso mostra que o tempo é visto como um "canibal solar" que se alimenta dos "tenros anos", relembrando o mito de Cronos - mais uma referência à Antiguidade clássica - que devorava os próprios filhos com receio de ser destronado por um deles.

Podemos então fazer uma comparação entre "Nam Sibyllam" e o poema "Death by Water", iniciando-a com o estabelecimento de uma cadeia metafórica na confluência entre Eliot, com "Death by Water", e Faustino, com "Nam Sibyllam", pois as ressonâncias entre os poemas se iniciam com semelhanças de cunho semântico. Em Eliot encontramos "Sibyllam", na anteriormente mencionada epígrafe, em referência à Sibila de Petrônio, e em Faustino, além do título, temos o adjetivo sibilante na décima linha do poema "Contra as salsas areias sibilantes”, numa provável referência à Sibila, mas também ao ato ou efeito de sibilar. Em Eliot, na primeira estrofe do poema, temos a "fortnight dead", uma referência ao corpo de Phlebas, morto há quinze dias; em Faustino, na primeira linha, temos "velho corpo", em referência a alguém que morreu afogado há certo tempo. Retornando para primeira estrofe de "Death by Water", na segunda linha, temos a palavra "swell" que significa "onda" ou "vaga", e em "Nam Sibyllam”, na décima quarta linha, encontramos a mesma palavra "vaga". Na segunda linha da se- 
gunda estrofe de "Death by Water" temos a palavra "Picked" que significa roído, picado ou despedaçado, em referência ao processo de decomposição dos ossos de Phlebas, e em "Nam Sibyllam", na primeira linha, encontramos a palavra "desfraldava", que, metaforicamente, faz referência à carne do indivíduo afogado que já está se despregando do corpo, apodrecendo. Em "Death by Water" temos, na quarta linha da segunda estrofe, "age and youth", que significa maturidade e juventude, em referência às lembranças que Phlebas teve, indo retrospectivamente de sua fase adulta à juventude, e em "Nam Sibyllam", na quarta linha, temos "tenros anos" em referência à juventude do morto, momento em que sua morte já se preparava. Em Eliot temos "Whirlpool", na quinta linha da segunda estrofe, que significa remoinho ou torvelinho, em referência ao corpo de Phlebas que estava sendo tragado, e em Faustino temos os "turbilhões", na décima segunda linha, que também vão "enrolar" aquele que se exprime no poema em primeira pessoa. E ainda, temos em Eliot, na terceira linha da terceira estrofe, "who was once", que significa "que foi um dia", em referência à morte e ao passado de Phlebas, e em Faustino temos, na sexta linha, a mesma referência às "lápides eloquentes de um passado".

De modo geral, os poemas apresentam semelhanças de cunho imagístico. O conjunto de imagens encontrado em "Death by Water" são: um naufrágio, a morte por afogamento, a incitação ao esquecimento, o mar, a inexorabilidade do tempo, a transitoriedade da vida, o vazio e o presságio. O naufrágio certamente faz parte de "Death by Water", pois ele é mencionado nas outras seções de "The Waste Land" e, de acordo com Chechinel (2012, p.115), há a imagem de um naufrágio inspirado na peça "A Tempestade" de Shakespeare, que se faz presente na IV seção: “A current under sea / Picked his bones in whispers. / As he rose and fell / He passed the stages of his age and youth / Entering the whirlpool." (ELIOT, 1950). Em "Nam Sibyllam”, o naufrágio não é tão explícito, mas pode ser inferido em razão da morte no mar, e que provavelmente ocorreu por afogamento: "Lá onde um velho corpo desfraldava”, que também evoca a presença marinha pela própria metáfora 
utilizada para exprimir a decomposição do corpo, "desfraldar". Em "Death by water" a morte do personagem, no caso Phlebas, é descrita logo no começo do poema: "Phlebas the Phoenician, a fortnight dead", porém a causa da morte por afogamento só é descrita na segunda estrofe: "A current under sea / Picked his bones in whispers."

A imagem do esquecimento aparece logo no começo do poema "Forgot the cry of gulls, and the deep sea swell / And the profit and loss.", pois com a morte todos os valores mundanos se desfazem. O corpo que morre em "Nam Sibyllam" passa pelo mesmo processo: "Lá onde em cada corpo vi gravadas / Lápides eloquentes de um passado / Ou de um futuro arguido pelos anos”, pois as memórias dele não lhe pertencem mais, ele não possui nem passado e muito menos futuro, nada mais é importante.

O mar é uma das imagens mais sugestivas, pois desempenha o papel de um cenário onde se desenrola o poema, e também pelo mar representar força e imperecibilidade. No poema de Eliot, na segunda estrofe "A current under sea / Picked his bones in whispers.", descreve o corpo de Phlebas arrastado por uma corrente marinha, que, de tão forte, picou-lhe ou roeu-lhe os ossos em surdina, ato que nos leva a outra imagem, a inexorabilidade do tempo, porque o mar, implicitamente também o tempo, é implacável, a ponto de destruir os corpos por completo: "Lá cândidos leões alvijubados / Às brisas temporais se espedaçavam / Contra as salsas areias sibilantes", como é descrito por Faustino em seu poema. E ainda, em Eliot, também na segunda estrofe "As he rose and fell / He passed the stages of his age and youth / Entering the whirlpool.", podemos encontrar a imagem do vazio, pois enquanto o corpo de Phlebas emergia e afundava, ele simbolicamente relembrava momentos de sua velhice e juventude até ser tragado por um redemoinho e sumir para sempre.

Um vazio similar é encontrado em Faustino: “Lá vi o pó do espaço me enrolando / Em turbilhões de peixes e presságios”, esse personagem, assim como Phlebas, também desaparece em meio aos turbilhões de criaturas marinhas, justamente a última imagem 
do poema: "Pois na orla do mundo as delatantes / Sombras marinhas, vagas, me apontavam". Estes dois últimos trechos de "Nam Sibyllam" são comentados por Benedito Nunes (1986, p.26), que afirma que há neles uma ambiguidade em razão da sinuosidade da palavra vaga, que tanto pode ser um substantivo que significa onda, quanto pode ser um adjetivo que significa algo indefinido ou sem precisão. Assim este vocábulo reforça a nota apocalíptica da agressividade com que o tempo se apodera dos corpos e afirma o sentido dominante e fascinante do poema.

Em "Death by Water" a imagem do presságio também se faz presente ao final do poema, pois o narrador vaticina: "Gentile or Jew / O you who turn the Wheel and look to windward, / Consider Phlebas, who was once handsome and tall as you"; tal fala se assemelha a uma profecia: aqueles que se creem responsáveis por suas próprias decisões e donos do próprio destino, que se lembrem de Phlebas, que um dia já foi belo e alto, mas agora é apenas um nada dentro do mar.

Como podemos perceber, na confluência entre Mário Faustino e T. S. Eliot, realizada por meio de um processo de leitura e tradução, Faustino apropriou-se de Eliot enquanto poeta, mas este fato não inferioriza o trabalho de Faustino, pelo contrário, a assimilação feita por ele deu origem a um novo poema, que é belo em decorrência de uma "modulação rítmica das mais perfeitas na poesia faustiniana” (CHAVES, 1986, p.104). De acordo com Kristeva (1974), uma obra literária, sob a ótica da intertextualidade, não é simplesmente um resultado da escrita de um único autor, é um nascimento decorrente do seu diálogo com outros textos e estruturas da própria linguagem. Faustino buscou uma fonte em Eliot, da qual se apropriou, transformando-a criativamente. 


\section{Notas}

1. Este lema foi inspirado na tradução que Ezra Pound fez da citação “日日新”, de Confúcio, "As the sun makes it new / Day by day make it new /Yet again make it new". CONFUCIUS. "In letters of gold on T'ang's bathtub". In: KENNER, Hugh. The poetry of Ezra Pound. Faber \& Faber, 1985, p. 130.

2. Transcrição do Poema "Death by Water" e de sua tradução publicadas no Suplemento Arte-Literatura da Folha do Norte de 22 de janeiro de 1950, n. 144.

\section{3. (Tradução nossa)}

4. A citação original utilizada na epígrafe de "The waste land" está escrita em grego e latim: "Nam Sibyllam quidem Cumis ego ipse oculis méis vidi in ampulla pendere, et cum illi pueri dicerent: $\Sigma i ́ \beta v \lambda \lambda \alpha \tau i ́ \theta \dot{\lambda} \lambda \varepsilon ı c_{\text {; }}$ respondebat illa:

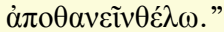

\section{Referências}

BENDER, Mires Batista. O homem e seu tempo na poesia de Mário Faustino. 2008. 169 p. Dissertação (Mestrado em Literaturas Brasileira, Portuguesa e Luso-africanas) - Universidade Federal do Rio Grande do Sul - Porto Alegre, 2008.

BOAVENTURA, Maria Eugênia. Um militante da poesia.In: BOAVENTURA, Maria Eugênia (Org.); FAUSTINO, Mário. O Homem e sua Hora e Outros Poemas. São Paulo: Companhia das Letras, 2009

CAMPOS, Haroldo de. Da tradução como criação e como crítica. In: Metalinguagem e outras metas. São Paulo: Perspectiva, 1992. 
CECHINEL, A. “A dramaticidade da poesia não dramática de T. S. Eliot: The waste land e outras observações”. Itinerários: Araraquara, n.34, p.109-121, Jan./June, 2012.

CHAVES, Albeniza. Tradição e modernidade em Mário Faustino. Belém: Universidade Federal do Pará, 1986. p. 104.

CHAVES, Lilia Silvestre. "O filósofo e o poeta". In: Bol. Mus. Para. Emílio Goeldi. Ciênc. hum.[online]. 2011, vol.6, n.2, pp. 377-393. ISSN 1981-8122. http://dx.doi.org/10.1590/S1981-81222011000200008.

COELHO, Marinilce Oliveira. Memórias literárias de Belém do Pará: o Grupo dos Novos, 1946-1952/. Campinas, SP: [s.n.], 2008

DICK, Susan et all. Ominium Gatheru: Essays dor Richard Ellmann. Gerrads Cross: Colin Smythe, 1989. P 149-150.

ELIOT, T. S. “Death by Water” (tradução de Mário Faustino). In: Suplemento Arte-Literatura do jornal Folha do Norte. Edição de 22 de janeiro de 1950, n. 144.

2004. p. 28.

. The complete poems and plays. Londres: Faber \& Faber Poetry,

FAUSTINO, Mário. Poesia Completa Poesia Traduzida.São Paulo: Max Limonad, 1985.

KRISTEVA, Julia. Introdução à Semanálise. São Paulo: Perspectiva, 1974.

MACHADO, Antonio. Juan de Mairena, Madrid 1986, XXIII, pág. 166.

NUNES, Benedito. A Clave do Poético. São Paulo: Cia das Letras, 2009b 1986, p. 26. . A obra poética e crítica de Mário Faustino. Belém: CEJUP, 
A poesia do meu amigo Mário. In: BOAVENTURA, Maria Eugênia (Org.); O Homem e sua Hora e Outros Poemas. São Paulo: Companhia das Letras, 2009a

NUNES, Benedito (Org.). "Nota sobre esta edição”. In: FAUSTINO, Mário. Poesia Completa Poesia Traduzida.São Paulo: Max Limonad, 1985, p. 10.

cia. São Paulo: Perspectiva, 1977, p. 278

.Poesia-experiência”.In: FAUSTINO, Mário. Poesia-experiên-

PETRÔNIO. Satyricon. Edição bilíngüe, tradução e posfácio de Sandra Maria G. B. Blanchet. Belo Horizonte: Editora Crisálida, 2004.

SANTIAGO, Silviano. O entre-lugar do discurso latino-americano. In: Uma literatura nos trópicos. São Paulo: Perspectiva, 1978.

SOUZA, Eneida Maria de. O discurso crítico brasileiro. In: Crítica Cult. Belo Horizonte: UFMG, 2002.

STOCK, Robert. A meretriz imaginária (tradução de Mário Faustino). Belém: Edição do Escriba, 2012.

Recebido em: 20/09/2014 Aceito em: 01/11/2014 